\title{
Examining the Correlation between American Students' Cultural Intelligence, Political Affiliations, and Their Social Distances from Their International Peers
}

\author{
Sami Mejri \\ Tiffin University, USA
}

\begin{abstract}
Guided by the theories of cultural intelligence and social distance, the purpose of this quantitative non-experimental study was to determine whether first-year Americanborn college students' political party affiliations and cultural intelligence (CQ) relate to their self-reported social distances (SDs) from international students. One hundred and twenty-one first-year college students at a 4-year Midwestern university participated in this study. Regression analysis showed that political party affiliation $(\beta=.194, t=3.074, p=.003)$, metacognitive CQ $(\beta=-.239, t=-.2 .885, p=.005)$, motivational CQ $(\beta=-.363, t=-4.225, p=.001)$, and behavioral CQ $(\beta=-.215, t=$ $-3.078, p=.003$ ) of American-born college students were statistically significant predictors of their social distances from international peers. However, cognitive CQ ( $\beta=.009, t=.112, p=.911)$ was not a statistically significant predictor of social distance between these two groups of students. Recommendations for future examination of CQ and SD in the context of American higher education were provided.
\end{abstract}

Keywords: American students, cultural intelligence, international students, international student mobility, political affiliation, social distance

Some scholars view education as one of the most effective vehicles for social mobility and competitiveness in today's globalized and knowledge-based economy (Brezis \& Hellier, 2018; Pfeffer, 2015). Others regard it as a liberating journey, which allows persons and groups of various cultural and national backgrounds to interact in ways 
that nurture their personal and cognitive developments (Butz \& Askim-Lovseth, 2015; Buzzelli, 2016). However, interactions between American students and their international peers is critical to the acculturation of the latter group due to the sociocultural, emotional, and educational challenges that they face (Fahad, 2015; Gautam, Lowery, Mays, \& Durant, 2016; Huhn et al., 2016).

The increase in international student enrollment at American higher education institutions has had positive economic impacts on the economy of the United States. According to a 2018 report by Open Doors, international students added 42 billion dollars to the U.S. economy during the 2016-2017 academic year (Institute of International Education [IIE], 2018). In addition to the economic value international students provide, their interactions with their American peers provide opportunities for cultural exposure critical to their career aspirations in today's global economy (Chao, Paiko, Zhang \& Zhao, 2017; Holtbrugge \& Engelhard, 2016). Furthermore, having international students as classmates or roommates may be fundamental in altering the biased beliefs and misperceptions that American students may have toward people of other nationalities (I-Ching, Ahn, Kim, \& Lin-Siegler, 2017; McFaul, 2016). Researchers have also emphasized the prominence of social interactions in shaping the acculturation processes and academic success of college students (Buzzelli, 2016; Tawagi \& Mak, 2015).

However, despite these research efforts, current literature has focused primarily on growth in enrollment numbers, its economic benefits, and the various processes of international students' acculturations (Buzzelli, 2016; E. J. Lee, 2016; Li, Heath, Jackson, Allen, Fischer \& Chan, 2017). There are limited investigations of the perceptions of American-born students toward their international counterparts, and ways in which cultural barriers can be bridged. This is not to say that American students and institutions are inclined to approach common challenges to international students, but most of the research focuses primarily on the views of and challenges faced by the latter group. To this end, such investigation would help improve acculturation and learning outcomes for both domestic and international students (Haugen \& Kunst, 2017; Li et al., 2017). This study shows that political party affiliation and three of the four dimensions of cultural intelligence (CQ) of Americanborn students were significant predictors of their self-reported social distances (SDs) from their international peers.

\section{LITERATURE REVIEW}

The pressure of competing for the recruitment of international learners coupled with an increase in student mobility, particularly from growing economies such as China and India, have led to a record level of enrollments of international students in the 2016-2017 academic year (Institute of International Education, 2018). IHowever, international students continue to face myriad challenges while studying in the United States, particularly concerning their sociocultural adjustments and integration (Buzzelli, 2016; E. J. Lee, 2016; Li et al., 2017; Shu, McAbee \& Ayman, 2017). Such challenges may limit the cross-cultural experiences between international and American-born students. Recent studies have shown that friendship formation and interactions among American and international students are mutually beneficial to 
both groups (Buzzelli, 2016; Imamura \& Zhang, 2014; Tawagi \& Mak, 2015). The purpose of this quantitative correlation study was to examine the relationship between the CQ of American students and their self-reported SDs from their international peers, considering whether political party affiliation is also a predictor of American students' sense of distance from their international peers.

\section{Envisioning the Globalized Classroom Environment}

Globalization has become one of the catchphrases of the $21^{\text {st }}$ century in both scholarly and popular discourses (Kacowicz \& Mitrani, 2016). Studies have examined who benefits and who loses from globalization within the context of an interdependent and interconnected world economy (Bergh, Mirkina, \& Nilsson, 2016; C. Lee, Lee, \& Chiou, 2017). For some, the emergence of globalization was similar to that of the capitalistic system, which has further divided the world into geopolitical structures of power and economic dependencies, thus widening the gap between the social classes (Antràs, de Gortari \& Itskhoki, 2017; Wu, Perrings, Kinzig, Collins, Minteer \& Daszak, 2017). For Bergh et al. (2016), globalization represents a socioeconomic phenomenon that reduces poverty, even in countries with low institutional quality. To this end, the paradoxical outlook on globalization has been shaped by the way in which resources and intellectual capital is being distributed around the world.

The rise of the network society, which was catalyzed by advancement in information technology and the subsequent increase in the use the Internet throughout the world, has revolutionized human connection (Baker, Warburton, Hodgkin \& Pascal, 2014). Globalization has catalyzed the computerized and digitalized nature of human connections (Baker et al., 2014; Antràs et al., 2017). From this standpoint, the social network provides a historical and logical framework for examining globalization, especially concerning the interconnectedness of social, economic, and educational spheres (Bergh et al., 2016). Globalization has reshaped the nature of educational policy and practice around the world through the increase in student mobility, presence of international branch campuses, and international baccalaureate programs (Healey, 2015; Menashy \& Dryden-Peterson, 2015). These international functions of the university altered the role of the educator, the learner, and the environment in which they interact.

\section{International Student Mobility}

International student mobility is a complex phenomenon that can be tied to sociocultural, political, and economic factors (Choudaha, 2017; Macrander, 2017; Prazeres et al., 2017). For Prazeres et al. (2017), the individual's desire and motivation for accumulating future economic and cultural capital is one of the primary pulling factors for student mobility. Prazeres et al. (2017) also posited that internationally mobile students are motivated by the competition for symbolic capital, which is associated with the place and the ranking of the college they attend. Employment, social benefits, and the political stability of both the student's country of origin and country of destination are also predictor factors for international student 
mobility (C. Lee et al., 2017; Okeja, 2017). However, international student mobility is not solely tied to economic and political factors.

In the case of China, which is the country of origin of the largest number of international students in the world with over 363,000 students in 2017 (IIE, 2018), researchers have claimed the existence of other cultural and historical push factors (Lee et al., 2017; Liu, 2016). For example, Liu (2016) examined the impacts of culture on student mobility and argued that China's education-first culture, as well as a saving culture and extended-family culture, continue to play an outbound factor. Ultimately, the US has become a top destination for Chinese international students, who constitute the majority of incoming sojourners (IIE, 2018).

The United States receives the largest number of international students, which accounts for more than a third of all international students around the world (IIE, 2018). However, changes in immigration policies and the political stance on immigration have created sporadic phases of inbound and outbound mobility for international students (Choudaha, 2017; Macrander, 2017). Choudaha (2017) examined the nature of student mobility to the United States over the past two decades and identified three phases of movements that are tied to significant events.

The 9/11 terrorist attack influenced the first phase of international student mobilization during the first decade of the 21st century (Choudaha, 2017). During this time, the U.S. government placed more restrictions on student visas, particularly from the Middle Eastern and North African countries. Given that 11 of the 19 hijackers were from the Middle East, these travel bans aimed at reducing terror threats and ensuring national and global security (Shammas, 2015). The second wave of inbound movement of international students took place during the 2008 financial recession, which triggered an economic motivation for the recruitment of international students (Choudaha, 2017; Macrander, 2017). This financial motivation is due to the fact that American systems of higher education have long struggled with funding their operational expenses and improving graduation rates while at the same trying to minimize tuition increases (Choudaha, 2017; Li, 2017). However, during and after the 2008 recession, appropriation per full-time equivalent had fallen by $23 \%$ in 48 out 50 states (Doyle \& Zumeta, 2014). This unprecedented decline in government funding made the recruitment of international students into U.S. higher education an alternative pathway for tuition revenue (Fabricius, Mortensen, \& Haberland, 2017; Gautam et al., 2016). The third phase of influence to outbound mobility was shaped by a myriad of economic and geopolitical events such as the UK's referendum to leave the European Union, a slowdown in the growth of rising economies, and the outcome of the recent U.S. elections (Choudaha, 2017).

These geopolitical events may not have a direct impact on the nature of crosscultural interactions between American students and their international counterparts. However, such events play a significant role in shaping the public's attitudes toward immigration and level of acceptance to people from other nationalities (Fuchs et al., 2014). For example, the racist and xenophobic rhetoric of the U.S.'s 2016 presidential campaign and the Trump administration's hard line stance on immigration, particularly from Muslim nations, only served to push back on globalism and support for isolationism (Ramswell, 2017). This nationalistic political approach changes the concept of globalization from a phenomenon that has allowed for the free movement 
of financial and intellectual capital to symptomatic of lost sovereignty, rights, and identities (C. Lee et al., 2017; Ramswell, 2017). This new wave of nationalistic and somewhat hostile political ideologies sought to demonstrate that nationalism and populism can serve the public by regaining its cultural identity and lost traditions (Ramswell, 2017). As indicated above, these political dynamics could potentially influence the American public's stand on immigration and shape the nature of crosscultural interactions with people of other nationalities, including international students (Fuchs, Dreher, \& Nunnenkamp, 2014; Ramswell, 2017; Rose-Redwood \& Rose-Redwood, 2017).

\section{Acculturation of Sojourners}

Researchers who have studied the lived experiences of international students have concluded that this population of students faces a variety of sociocultural, psychological, and educational challenges (Fahad, 2015; Huhn et al., 2016; RoseRedwood et al., 2017; Zhen et al., 2017). International students come from different countries and are accustomed to different values, codes of attitudes and behavior, and different cultural and religious backgrounds and thus may not be fully integrated into American higher education (E. J. Lee, 2016; Li et al., 2017; Lombard, 2014; Zabo, Ward, \& Jose, 2016). Additionally, the academic and cultural inclusiveness of international students may depend in part on the quality and frequency of interactions with their American peers (E. J. Lee, 2016).

\section{Sociocultural Challenges}

Researchers have revealed that students studying abroad face a variety of sociocultural and emotional problems (Bierwiaczonek, Waldzus, \& Zee, 2017; Fahad, 2015; Gautam et al., 2016; Huhn et al., 2016). In a quantitative study, Imamura and Zhang (2014) found that domestic students were more willing to communicate with their Chinese counterparts, only if the latter group was assimilated into the American way of life (Imamura \& Zhang, 2014). American students considered assimilation to American culture as speaking with a clear accent, being able to engage in group discussions, and being understood (Imamura \& Zhang, 2014; E. J. Lee, 2016).

In more distressing studies, international students have identified themselves as subject to prejudice as a result of threats, social dominance, and right-wing authoritarianism by their domestic counterparts (Bierwiaczonek et al., 2017; CharlesToussaint \& Crowson, 2010). Brown and Jones (2013) also examined the various occurrence of racism and religious discrimination that international students experience while studying abroad. Using survey research, the study concluded that international students, particularly those from Arabic-speaking countries, have experienced various forms of verbal and physical abuse (Brown \& Jones, 2013). However, issues related to social and academic inclusion are not always limited to religious affiliation and national origin (Ching et al., 2017). There exists a wide range of psychological, emotional, and intellectual challenges (Ching et al., 2017; E. J. Lee, 2016; Li et al., 2017). In another study, Geary (2016), who has lived the international 
student experience, indicated that social connections, adjustment to new cultures, and overcoming linguistic hurdles were the primary challenges facing international students.

\section{Educational Challenges}

Sixty percent of international students come from countries where English is not the primary language (IIE, 2018). Ultimately, one of the obvious educational challenges for international students studying in the U.S. is how and to what extent they grasp the English language (Butz \& Askim-Lovseth, 2015; Gautam et al., 2016; Geary, 2016; Imamura \& Zhang, 2014). However, the use of technology and appropriate teaching strategies have proven useful in reducing language anxiety for international students (E. J. Lee, 2016; Gautam et al., 2016). For example, E. J. Lee (2016) examined the impacts of teachers' corrective feedbacks on student's anxiety about speaking English. Findings from this study showed that most of the teacher's feedback lowered student anxiety about the language (E. J. Lee, 2016).

In a similar study, Butz and Askim-Lovseth (2015) used a hybrid learning environment to compare the oral communication skills of international students based on the modality of instruction. Findings from this study showed that international students in the hybrid environment outscored their counterparts in the face-to-face environment (Butz \& Askim-Lovseth, 2015). As such, future research should consider the use of computer-aided instructions as a platform for promoting crosscultural engagements and the acculturation of international students. Additionally, information technology, which offers students opportunities for virtual interactions, is a vehicle for reducing communication anxiety and the fear of social exclusion (Huhn et al., 2016).

\section{Attitudes and Perceptions toward International Students}

From a global standpoint, Stein and Andreotti (2016) offer the concept of "global imaginaries" as the explanation for the passionate recruitment of international students, who oftentimes encounter experiences of racism and alienation. This conceptual image is rooted in the history of Western supremacy and economic dominance for many centuries (Stein \& Andreotti, 2016). Within this image of political and economic hierarchy, the Western world is viewed as the paradigm for humanity and technological advancements, while the rest of the world tails behind (Collier, Rosch, \& Houston, 2017; Tan, \& Chua, 2015).

\section{The Ideological Frameworks of Western Supremacy}

Based on the argument that Stein and Andreotti (2016) presented, the term "racism" here is not used in the context of discrimination by members of the host country (i.e., students, faculty, and staff). Rather, the term is indicative of the inherited nature of such perceptions toward the international learner (Stein \& Andreotti, 2016). These structured and racialized logics place Western higher education as a globally desirable product that provides economic incentives for 
recruiters of international students, while at the same time exposing the biases and contradictions that are associated with the recruitment and sociocultural alienations (Stein \& Andreotti, 2016).

This perception of influence and dependence on Western ideals is also echoed in the field of comparative and international education, particularly in the area of global aid for education and international assessments (Pfeffer, 2015; Shields \& Menashy, 2019). Shields and Menashy (2019) argued that the flow of aid is based on former colonial relationships and that motivation for resource allocation is structured around the political, economic, and security interests of donor states. To some critics, global aid for education establishes an extension of existing colonial relationships whereby education becomes a vehicle for assertion and preservation of the normative views and narrative of former colonial powers (Pfeffer, 2015).

\section{Perceptions and Attitudes Toward International Sojourners}

In higher education, the attitudes and perceptions of host-national students, faculty, and staff toward international students play a critical role in shaping the lived experiences of international students (Bierwiaczonek et al., 2017; E. J. Lee, 2016; Li et al., 2017). E. J. Lee (2016) examined the perceptions of American and international students about the benefits of informal English conversations and found that international students have gained augmented linguistic and cultural skills when engaging with their peers (E. J. Lee, 2016). On the other hand, American students reported that cultural awareness was the primary benefit from the conversations and that they were less likely to engage with international students who seemed unassimilated to the American culture (E. J. Lee, 2016). Ruble and Zhang (2013) found that American students hold stereotypical beliefs about Chinese students. The authors conducted exploratory factor analysis, which revealed five primary stereotypes about international students, including that they are smart, hardworking, shy, have bad English skills, and are not assimilated (Ruble \& Zhang, 2013).

In examining the attitudes and perceptions of American students toward their international peers, it is important to point out that race, nationality, and religious beliefs of the latter group play an important role in shaping the views and attitudes of their American peers (E. J. Lee, 2016; Li et al., 2016; Shammas, 2015). For example, after 9/11, Arabs and Muslims living in the United States have been the primary targets of the government's national security and counterterrorism program. Over the past two decades, a series of highly charged events, including the ongoing wars in Iraq, Afghanistan, and the toppling of dictatorship regimes in the Middle East and North Africa, have led to the curtailment of civil rights of Muslim student organizations (Fahad, 2015). In 2013, two men from the former Soviet State of Kyrgyzstan conducted a terrorist attack against Marathon runners in Boston Massachusetts. These events have also given rise to an anti-Arab and anti-Muslim discourse in American society (Fahad, 2015; Shammas, 2015). The political rhetoric seeps into the attitudes of the American way of life, particularly as it relates to higher education and the nature of intergroup contacts between national and international student groups (Ron, Solomon, Halperin, \& Saguy, 2017; Shammas, 2015). 
However, it is also fair to point out that the attitudes and perceptions of American-born students have not always been negative toward their international peers. American-born students' attitudes toward their international peers seem to be more positive when it comes to athletics and collaborative sporting events (Buzzelli, 2016; Foo, Wells \& Walker, 2015). Foo et al. (2015) showed that American students did not hold negative views concerning the recruitment of international studentathletes (Foo et al., 2015). Additionally, Rice at al. (2016) found that there was no significant difference between domestic and international students concerning the building of advising alliances. These findings confirm the hypothesis developed by Allport (1979) and those of Pettigrew and Tropp (2006) that the existence of a common goal between social groups is critical to enhancing intergroup relations.

As to perceptions and attitudes of faculty and staff toward international students, the findings tend to vary based on the context and whether the views were related to classroom interactions or academic assessments (Sheppard, B. E., Elliott, \& BaeseBerk, 2017). College faculty's assessment of international students' abilities differs across disciplines and focus areas of study. For example, Sheppard et al. (2017) examined college faculty's attitudes and perceptions of international students' speech and comprehension and concluded that these skills differed based on their areas of specializations. English for Academic Purposes Instructors (EAP) and content faculty listened to international students' speeches and provided comprehensibility ratings for international students. Sheppard et al. (2017) found that comprehensibility ratings and intelligibility scores for both groups were similar, but EAP instructors were able to transcribe more accurately for less fluent speakers (Sheppard et al., 2017). Furthermore, content faculty with more negative attitudes toward EAP learners provided lower ratings (Caplan \& Stevens, 2017; Sheppard et al., 2017).

\section{RESEARCH METHOD}

The increasing trend of international student mobility, particularly toward the US, has given rise to scholarly discussions concerning cross-cultural interactions within educational spheres, as well as the importance of developing cultural competency in today's interconnected and knowledge-based economies (Holtbrugge \& Engelhard, 2016). International students continue to face a myriad of sociocultural challenges, including building friendships with American-born peers (I-ching et al., 2017; E. J. Lee, 2016; Tawagi \& Mak, 2015). As such, depending on their background variables, $\mathrm{CQ}$, and self-reported SD from international peers, the American-born student could play a significant role in reducing such challenges and developing cross-cultural competencies (Chao et al., 2017).

\section{Population and Sample}

To determine the minimum required sample for the study, a $G^{*}$ Power analysis using five predictors of Social Distance, an effect size of .15 and an alpha value of .05 showed that a minimum sample of 92 participants was needed. Although, 92 responses were needed, a total of 121 students out of a total of 689 undergraduate first-year American-born students who were enrolled at a small private Mid-western 
university participated in the study. Of the first-year students, $46 \%$ identified themselves as White, $15 \%$ as Black, $4 \%$ as Hispanic/Latino, and $24 \%$ as unknown, $1 \%$ as Asian, $1 \%$ more than one race, and $10 \%$ international students. Fifty-four percent of the students identified themselves as females and $46 \%$ as males. The total on-campus population at the selected university for this study consisted of approximately 4,100 undergraduate students and 1,000 graduate students. During the 2016-2017 school year, a total of 380 international students representing 27 countries were enrolled in both graduate and undergraduate programs at the university (Center for International Affairs, 2016). Due to F1-visa sponsorship and other regulations, most international students are not permitted to enroll in online courses. As such, American-born students who were enrolled in online programs would have little to no interaction with international students, and thus only students who were enrolled in the face-to-face courses were invited to participate in the research study. Additionally, American-born students who have lived outside the US for more than 3 months, as students or visitors, were not eligible to participate in this study. The reason for this exclusion is that travel experiences may have changed the perceptions and views of American-born students toward people of other cultures and nationalities. Given the categorical and continuous nature of the variables, the analysis was based on multiple linear regression with five predictors; an assumed medium-effect size, a power level of .80 , and a significance level of .05 . Table 1 provides a summary of the parameters for the outcome of the final sample size for this study.

\section{Table 1: Power Analysis}

\begin{tabular}{lc}
\hline Parameter & Value \\
\hline Predictors & 5 \\
Effect size & .15 \\
Alpha & .05 \\
Power & .80 \\
Total sample size & 92 \\
\hline
\end{tabular}

\section{Material/Instrumentation}

The survey instrument consisted of a CQ component, a SD component, and a demographic component. Early and Ang's (2003) 20-item questionnaire with a composite reliability and validity exceeding .70 was used to measure CQ (Van Dyne \& Ang, 2008; Van Dyne et al., 2012). The CQ questionnaire is in the form of a Likertscale ranging from one to seven $(1=$ strongly disagree, $7=$ strongly agree $)$. The survey instrument included the CQ scale of Van Dyne and Ang's (2008), which is a 20 -item self-report measure designed to measure an individual self-scoring on the four dimensions of CQ. The four dimensions are metacognitive CQ (four items; Cronbach's $\alpha=.80$ ), cognitive CQ (six items; Cronbach's $\alpha=.82$ ), motivational CQ (five items; Cronbach's $\alpha=.76$ ), and behavioral CQ (five items; Cronbach's $\alpha=.78$ ).

The instrument also included a SD component and a demographic component. The metacognitive CQ items (e.g., "I am conscious of the cultural knowledge I use 
when interacting with people with different cultural backgrounds"), cognitive CQ items (e.g., "I know the legal and economic systems of other cultures"), motivational CQ items (e.g., "I enjoy interacting with people from different cultures"), and behavioral CQ items (e.g., "I change my verbal behavior [e.g., accent, tone]) when a cross-cultural interaction requires it"). The most recent CQ list, which was developed by Ang et al. (2007), appears in Appendix A. Presbitero (2016) also used the CQ questionnaire to show that CQ moderates culture shock and reverse culture shock of students. Shu et al. (2017) also used the same survey to show that CQ is a predictor of cross-cultural adjustments. Although researchers have used several different forms of cultural assessment tools, the instrument that Van Dyne et al. (2012) created is the most valuable for this study.

The second tier of the instrument consists of a 12-item rating scale of SD, which is an updated version of the Bogardus SD scale that was adopted by Norman, Windell, and Manchanda (2012). This section of the survey consists of a scale ranging from one to five $(1=$ I certainly would, $5=$ I certainly would not $)$ and has an established reliability of .081 (Yoshii, Mandai, Saito, \& Akazawa, 2015). To use SD as a dependent variable in the multiple regression, a composite score of the responses was computed. The third layer of the survey consists of three background questions, and political party affiliation represents one of the independent variables.

\section{RESULTS}

To address the research questions, multiple regression analysis and an analysis of variance (ANOVA) were conducted to identify significant correlations between the dependent and independent variables. The backward option was entered into SPSS to ensure that only significant correlations were identified. Multiple linear regressions were calculated to predict the SD of American-born students based on their political party affiliations and the four dimensions of CQ. Based on Model 2, as shown in Tables 3 and 4, a significant regression equation was found, $F(4,117)=38.932, p<$ .001 , with an $R^{2}$ of .571 . The multiple regression equations indicate the existence of a statistical relationship between one or more predictor variables and the dependent variable.

Following the tests of assumptions, the significance of the overall regression model was evaluated using the $F$ test at a significance level of .05 . Additionally, $R^{2}$ was computed to determine the proportion of variability in criterion variable scores by the set of predictor variables (i.e., four dimensions of CQ and political party affiliation). The overall backward model was used and four predictors (metacognitive $\mathrm{CQ}$, behavioral $\mathrm{CQ}$, motivational $\mathrm{CQ}$, and political party affiliation showed significance, and cognitive CQ was the predictor that was not significant, as shown in Table 2. 
Table 2: Model Summary

\begin{tabular}{|c|c|c|c|c|c|c|c|c|c|}
\hline \multirow[b]{2}{*}{ Model } & \multirow[b]{2}{*}{$R$} & \multirow[b]{2}{*}{$R^{2}$} & \multirow[b]{2}{*}{$\begin{array}{c}\text { Adjusted } \\
R^{2}\end{array}$} & \multirow[b]{2}{*}{$\begin{array}{c}S E \text { of } \\
\text { est. }\end{array}$} & \multicolumn{5}{|c|}{ Change statistics } \\
\hline & & & & & $\begin{array}{c}R^{2} \\
\text { change }\end{array}$ & $\begin{array}{c}F \\
\text { change }\end{array}$ & $d f_{1}$ & $d f_{2}$ & $\begin{array}{l}\text { Sig. } F \\
\text { change }\end{array}$ \\
\hline 1 & $.756^{\mathrm{a}}$ & .571 & .553 & .50923 & .571 & 30.885 & 5 & 116 & .000 \\
\hline 2 & $.756^{\mathrm{b}}$ & .571 & .556 & .50707 & .000 & .013 & 1 & 116 & .911 \\
\hline
\end{tabular}

Note . The dependent variable was social distance. Est. = estimate; Sig. = significant. aPredictors: (Constant), Political, Cognitive, Metacognitive, Behavioral, Motivational

${ }^{\mathrm{b}}$ Predictors: (Constant), Political, Metacognitive, Behavioral, Motivational

Individual model coefficients were evaluated at a significance level of .05. The sign of the B coefficients informs the direction of the relationship between the variables. The above statement meant that a positive relationship is shown in the proportional increase in the scores of the criterion and the predictor variables. Negative coefficients indicate that as scores on the predictor variables increase, scores of the criterion variable decrease. The significance of the model coefficients corresponding to political party affiliation, the four dimensions of CQ and SD, were used to test the research questions respectively.

Research Question 1: What is the relationship between American-born students' reported political party affiliation and their self-reported SD from international peers?

Hypothesis 1: There is no relationship between the political party affiliation of American-born students and their self-reported social distances from international students.

Based on Model 2 of the coefficient Table 3, political party affiliation was found to be a statistically significant positive predictor of $\mathrm{SD}(\beta=.194, t=3.074, p=.003)$. This means that the students' SDs increased by .194 units as political affiliation increased by one unit in the political affiliation spectrum. The political spectrum ranges from $(0=$ extremely liberal, Democrat; to $100=$ extremely conservative, Republican). These findings suggest that SD tend to increase as political party affiliation moves from liberal to conservative. Ultimately, H1 was rejected.

Table 3: Analysis of Variance

\begin{tabular}{clccccc}
\hline Model & & $\begin{array}{c}\text { Sum of } \\
\text { squares }\end{array}$ & $d f$ & $\begin{array}{c}\text { Mean } \\
\text { square }\end{array}$ & $F$ & Sig. \\
\hline 1 & Regression & 40.044 & 5 & 8.009 & 30.885 & $.000^{\mathrm{a}}$ \\
& residual total & 30.080 & 116 & .259 & & \\
2 & & 70.125 & 121 & & & \\
& Regression & 40.041 & 4 & 10.010 & 38.932 & $.000^{\mathrm{b}}$ \\
& residual total & 30.083 & 117 & .257 & & \\
& & 70.125 & 121 & & & \\
\hline
\end{tabular}

Note. The dependent variable was social distance. Sig. = significant. 
aPredictors: (Constant), Political, Cognitive, Metacognitive, Behavioral, Motivational

${ }^{\mathrm{b}}$ Predictors: (Constant), Political, Metacognitive, Behavioral, Motivational

Research Question 2: What is the relationship between the metacognitive CQ of American-born students and their self-reported SD from international peers?

Hypothesis 2: There is no relationship between the metacognitive CQ of American-born students and their self-reported social distances from international students.

Based on Model 2 of the coefficient Table 3, metacognitive CQ was found to be a statistically significant negative predictor of $\mathrm{SD}(\beta=-.239, t=-.2 .885, p<.005)$. These results meant that the students' SD decreased by .239 units as their metacognitive CQ increased by one unit. Given these findings, $\mathrm{H} 2$ was rejected. The metacognitive variable was computed as the average score of four questions on the responders' consciousness about and adjustments to cultural situations.

Research Question 3: What is the relationship between the cognitive CQ of American-born students and their self-reported SD from international peers?

Hypothesis 3: There is no relationship between the cognitive CQ of American-born students and their self-reported social distances from international students.

Based on Model 2 of Tables 3 and 4 of the excluded variables, cognitive CQ was found not to be a statistically significant predictor of $\mathrm{SD}(\beta=.009, t=.112, p=.911)$. These results meant that the students' SDs decreased by .009 units as their cognitive $\mathrm{CQ}$ increased by one unit. Consequently, $\mathrm{H} 3$ was not rejected. The cognitive variable was computed as the average score of six questions of the CQ questionnaire, which focused on an individual's factual knowledge about other cultures and norms. 


\section{Table 4: Coefficients}

Coefficients $^{2}$

\begin{tabular}{|c|c|c|c|c|c|c|c|c|c|c|c|c|c|}
\hline \multirow{2}{*}{\multicolumn{2}{|c|}{ Model }} & \multicolumn{2}{|c|}{$\begin{array}{l}\text { Unstandardized } \\
\text { Coefficients }\end{array}$} & \multirow{2}{*}{$\begin{array}{c}\begin{array}{c}\text { Standardiz } \\
\text { ed } \\
\text { Coefficient } \\
\text { s }\end{array} \\
\text { Beta } \\
\end{array}$} & \multirow[b]{2}{*}{$t$} & \multirow[b]{2}{*}{ Sig. } & \multicolumn{2}{|c|}{$\begin{array}{l}95.0 \% \text { Confidence } \\
\text { Interval for B }\end{array}$} & \multicolumn{3}{|c|}{ Correlations } & \multicolumn{2}{|c|}{ Collinearity Statistics } \\
\hline & & B & Std. Error & & & & $\begin{array}{l}\text { Lower } \\
\text { Bound }\end{array}$ & $\begin{array}{l}\text { Upper } \\
\text { Bound }\end{array}$ & Zero-order & Partial & Part & Tolerance & VIF \\
\hline \multirow[t]{6}{*}{1} & (Constant) & 4.519 & .279 & & 16.182 & .000 & 3.966 & 5.072 & & & & & \\
\hline & Metacognitive & -.161 & .057 & -241 & -2.849 & .005 & .273 & .049 & .607 & -.256 & -.173 & .518 & 1.930 \\
\hline & Cognitive & .006 & .049 & .009 & .112 & .911 & .092 & .103 & -.415 & .010 & .007 & .615 & 1.627 \\
\hline & Motivational & .253 & .061 & -365 & .4 .140 & .000 & .374 & -132 & .665 & .359 & .252 & .476 & 2.100 \\
\hline & Behavioral & -137 & .047 & -.218 & -2.887 & .005 & -.231 & -.043 & .525 & -.259 & -.176 & 649 & 1.540 \\
\hline & Political & .005 & .002 & .193 & 3.023 & .003 & .002 & .008 & .371 & 270 & .184 & .911 & 1.098 \\
\hline \multirow[t]{5}{*}{2} & (Constant) & 4.517 & .278 & & 16.275 & .000 & 3.967 & 5.067 & & & & & \\
\hline & Metacognitive & -.160 & .055 & -.239 & -2.885 & .005 & -.270 & .050 & -607 & -.258 & -.175 & .534 & 1.873 \\
\hline & Motivational & -251 & .060 & -363 & -4.225 & .000 & .369 & -134 & .665 & -364 & -.256 & .497 & 2.011 \\
\hline & Behavioral & .135 & .044 & -.215 & -3.078 & .003 & .221 & .048 & .525 & .274 & .186 & .753 & 1.328 \\
\hline & Political & .005 & .002 & .194 & 3.074 & .003 & .002 & .008 & .371 & .273 & .186 & .925 & 1.081 \\
\hline
\end{tabular}

Table 5 of the stepwise regression analysis also shows that cognitive CQ was the only excluded variable, which indicates its non-statistical significance for predicting SD. The non-significance of cognitive CQ meant that American student's factual knowledge about the cultural norms and traditions of international students was not a predictor of their self-perceived SD toward them.

Table 5: Excluded Variables

\begin{tabular}{ccccccccc}
\hline & & & & & & \multicolumn{2}{c}{ Collinearity statistics } \\
\cline { 7 - 9 } Model & & Beta & & & Partial & & & Min. \\
in & & $t$ & Sig. & correlation & Tolerance & VIF & tolerance \\
\hline 2 & Cognitive & $.009^{\mathrm{a}}$ & .112 & .911 & .010 & .615 & 1.627 & .476 \\
\hline
\end{tabular}

Note. The dependent variable was social distance. Sig. = significance; Min. $=$ minimum.

apredictors: (Constant), Political, Metacognitive, Behavioral, Motivational 


\section{Table 6: Model Summary}

\begin{tabular}{|c|c|c|c|c|c|c|c|c|c|c|}
\hline \multirow[b]{2}{*}{ Model } & \multirow[b]{2}{*}{$\mathrm{R}$} & \multirow[b]{2}{*}{ R Square } & \multirow[b]{2}{*}{$\begin{array}{c}\text { Adjusted R } \\
\text { Square }\end{array}$} & \multirow{2}{*}{$\begin{array}{l}\text { Std. Error } \\
\text { of the } \\
\text { Estimate }\end{array}$} & \multicolumn{5}{|c|}{ Change Statistics } & \multirow[b]{2}{*}{$\begin{array}{l}\text { Durbin- } \\
\text { Watson }\end{array}$} \\
\hline & & & & & $\begin{array}{c}\text { R Square } \\
\text { Change }\end{array}$ & F Change & df1 & $d f 2$ & $\begin{array}{l}\text { Sig. F } \\
\text { Change }\end{array}$ & \\
\hline 1 & $.665^{\mathrm{a}}$ & .442 & 438 & .57079 & .442 & 95.238 & 1 & 120 & .000 & \\
\hline 2 & $.709^{b}$ & .502 & .494 & .54154 & .060 & 14.315 & 1 & 119 & .000 & \\
\hline 3 & $.735^{\mathrm{C}}$ & .540 & .529 & .52257 & .038 & 9.797 & 1 & 118 & .002 & \\
\hline 4 & $.756^{d}$ & .571 & .556 & .50707 & .031 & 8.321 & 1 & 117 & .005 & 1.744 \\
\hline \multicolumn{11}{|c|}{ a. Predictors: (Constant), Motivational } \\
\hline \multicolumn{11}{|c|}{ b. Predictors: (Constant), Motivational, Behavioral } \\
\hline \multicolumn{11}{|c|}{ c. Predictors: (Constant), Motivational, Behavioral, Political } \\
\hline \multicolumn{11}{|c|}{ d. Predictors: (Constant), Motivational, Behavioral, Political , Metacognitive } \\
\hline \multicolumn{11}{|c|}{ e. Dependent Variable: Social Distance } \\
\hline
\end{tabular}

Research Question 4: What is the relationship between the motivational CQ of American-born students and their self-reported SD from international peers?

Hypothesis 4: There is no relationship between the motivational CQ of American-born students and their self-reported social distances from international students.

Motivational CQ was found to be a statistically significant predictor of SD $(\beta=-.363$, $t=-4.225, p<.001)$. These results meant that SD between American-born students and their international peers decreased as motivational CQ increased. Specifically, SD decreased by .363 units as motivational CQ increased by one unit. The motivational variable was computed as the average score of five questions in the motivational dimension of CQ. Based on these results, H4 was rejected.

Research Question 5/hypothesis 5: What is the relationship between the behavioral CQ of American-born students and their self-reported SD from international peers?

Hypothesis 5: There is no relationship between the Behavioral CQ of American-born students and their self-reported social distances from international students.

Based on Model 2 of Table 3, behavioral CQ was found to be a statistically significant predictor of SD $(\beta=-.215, t=-3.078, p=.003)$. These results showed that SD between American-born students and their international peers decreased as motivational CQ increased. Specifically, SD decreased by .363 units as motivational CQ increased by one unit. Based on these results, H5 was also rejected. 


\section{Evaluation of the Findings}

Statistical analysis for this study showed that political party affiliation was a significant predictor variable for American-born students' self-reported SD from their international peers. Specifically, SD increased as the affiliation shifted from liberal to conservative. The findings of this study were in alignment with existing research that there is a growing anti-immigration stance in the United States and other parts of the Western world (Choudaha, 2017; Macrander, 2017). Events like the 9/11 attack, the Boston Marathon bombing, and the recent ban on immigrants from predominately Muslim countries may have shaped public views and perceptions about foreign nationals, at least among conservatives (Shammas, 2015). However, other circumstances such as difficulty in communicating with students of different nationalities and the limited nature of training specific to these types of intergroup interactions may also have been a factor in the outcomes.

The analysis also showed that metacognitive CQ was a statistically significant predictor of students' self-perception of their SD from their international peers. This finding also echoes those of Tawagi and Mak (2015) and Shu et al. (2017) that adjustment to and being conscious about one's cultural knowledge is critical to the quality of interactions between social groups. To this end, American-born students who have scored high on this dimension of CQ seemed to have a perception of closeness to their international peers (Buzzelli, 2016; Michalec, Giordano, Dallas, \& Arenson, 2017).

When it comes to cognitive CQ, results showed that this dimension was not a significant predictor of the SD. Cognitive CQ focuses on the individual's factual knowledge about the legal and social norms of other cultures, and not so much on the quality of interaction between groups (Engle \& Nash, 2016). The findings reiterated the fluid and transferable nature of cultural phenomena as a concept that builds on interactions rather than factual knowledge. For example, Racicot and Ferry (2016) found that increased opportunities for cultural exposure lead to higher levels of cognitive CQ. In a similar study about the role of language in intercultural communication, Presbitero (2017) found that while language ability plays an important role, motivational CQ plays an even more prominent role in attaining those tasks.

The next two predictors of SD were motivational and behavioral CQ. Both independent variables were computed as the average score of responses to questions relating to an individual's ability to acquire and adopt behaviors and attitudes that are appropriate for interacting with a new culture (Engle \& Nash, 2016). The findings of the study echoed those of Presbitero (2017) that training, sensitivity, personal, and professional intergroup contact reduce SD and unconscious biases.

From a theoretical perspective, the findings of this study suggest that the researcher was able to bridge the theories of $\mathrm{CQ}$ and $\mathrm{SD}$, thus creating a new framework for predicting and assessing intergroup contact based on cultural and demographic circumstances. The theory of CQ has been used as a framework for predicting job satisfaction (Presbitero, 2017; Ramsey \& Lorenz, 2016). In other studies, CQ was used to study students' levels of satisfaction with study abroad programs (Racicot et al., 2016). In the area of cross-cultural affairs, CQ has been used 
in the context of language anxiety and cultural adaptation (Harwood et al., 2017; Schumann, Klein, Douglas, \& Hewstone, 2017; White et al., 2015). Through this study, the research has built on existing frameworks and areas of interest to provide an approach for bridging the theories of CQ and SD within the context of higher education in the United States.

\section{CONCLUSIONS AND IMPLICATIONS}

As global society becomes more mobilized, millions of people travel across political and cultural boundaries in search for educational opportunities (The World Bank, 2017).This reaffirms the role of education in building cultural and intellectual capital through international student mobility (Fabricius, Mortensen \& Haberland, 2017). However, international students studying in the United States continue to face sociocultural challenges because of how their American-born peers perceive them (IChing, Ahn, Kim, \& Lin-Siegler, 2017; E. J. Lee, 2016; Tawagi \& Mak, 2015).

International students experience isolation and difficulty in making and maintaining close SD with American-born students and local communities, both of which present significant challenges to their sociocultural adjustments and academic engagements (Chao, Paiko, Zhang, \& Zhao, 2017; E. J. Lee, 2016; Wang, Heppner, Wang et al., 2015). Without focused assistance in inclusion and engagement, international students may continue to face acculturation challenges and experience social isolation, which could lead to withdrawal and disengagement from the learning process (E. J. Lee, 2016; Li et al., 2017; Tawagi \& Mak, 2015; Wang et al., 2015). Additionally, a significant decline in international enrollment would adversely affect existing jobs and the more than 35 billion dollars that recent enrollment numbers have added to the U.S. economy (IIE, 2015; NAFSA, 2016).

One of the limitations of this study, which may have constituted a threat to external validity, was the choice of a quantitative research method instead of using a qualitative or mixed-method approach. This limitation is inherent in the intertwining nature of qualitative and quantitative research designs in that neither method alone can provide scholars and readers with a comprehensive understanding of the studied phenomenon (Creswell, 2013). However, to achieve objectivity in capturing the perceptions of American-born students about their international peers, the quantitative design method was an appropriate approach to testing the research hypotheses. Another limitation, which constitutes a threat to internal validity, is the data was gathered through student self-reporting, which suggests the potential of susceptibility to social desirability and bias (Brenner \& DeLamater, 2016).

\section{Recommendations for Practice}

Recommendation for practice derives from the uniqueness of this study. The researcher has not come across any research design that uses CQ and SD in the context of higher education. Researchers who have studied the educational and cultural experiences of international students have done so from the perspective of international students, and almost none of the explored literature has focused on the views of American students. Findings from this study are important in the sense that 
the relationship between CQ and SD is not limited to students and higher education. This research design may be replicated by industries and corporations where interactions between Americans and people of other nationalities are critical to the success of the company (Aberson, 2015; Presbitero, 2017). Airline companies, law enforcement agencies, medical facilities, etc. could replicate this study to assess the SDs of their employees from customers of other nationalities.

Another recommendation for practice is that institutions of higher education could use this survey instrument as a method for assessing and promoting cultural awareness and sensitivity among students. In this cross-section correlation study, the sample was American-born students who were enrolled in their first year of college. One of the exclusion criteria was that participant has not lived outside the United States as students or visitors for more than 3 months. These frameworks were based on the fact that travel experiences and study abroad programs increased an individual's cultural competencies, which would have skewed the findings (Oyserman, 2016; Roy et al., 2017).

One recommendation for future research is to conduct a longitudinal study, which would assess how the relationship between CQ and SD changes over time. A lagged study may inform on the impacts, if any, of institutional training on intergroup contacts. The same study could also be replicated, but instead of using Americanborn students as the target population, researchers could study American-born faculty or staff. Future research may also seek to focus on intervention strategies and identify those that are effective in promoting cultural competencies and reducing misperceptions across social groups (Tawagi \& Mak, 2015). Finally, future research may capitalize on the use of the Internet in amplifying the frequency and speed of social interactions, which can play a critical role in improving intergroup relations (Harwood et al., 2017; Schumann et al., 2017). In conclusion, it is important for faculty and administrators in higher education institutions to recognize the role of social and cultural constructs such as political affiliation and cultural intelligence in predicting the level of connectedness between students of different nationalities.

\section{REFERENCES}

Aberson, C. L. (2015). Positive intergroup contact, negative intergroup contact, and threat as predictors of cognitive and affective dimensions of prejudice. Group Processes \& Intergroup Relations, 18(6), 743-760. doi: $10.1177 / 1368430214556699$

Allport, G. W. (1979). The nature of prejudice. New York: Basic Books.

Antràs, P., de Gortari, A., \& Itskhoki, O. (2017). Globalization, inequality and welfare. Journal of International Economics, 10(8), 387-412. doi:10.1016/j.jinteco.2017.07.009

Baker, S. Warburton, J., Hodgkin, S., \& Pascal, J. (2014). Reimagining the relationship between social work and information communication technology in the network society. Australian Social Work, 67(4), 467-478. https://doiorg.tu.opal-libraries.org/10.1080/0312407X.2014.928336 
Bergh, A., Mirkina, I., \& Nilsson, T. (2016). Do the poor benefit from globalization regardless of institutional quality? Applied Economics Letters, 23(10), 708-712. doi:10.1080/13504851.2015.1102835

Bierwiaczonek, K., Waldzus, S., \& Zee, K. D. (2017). Protective or harmful? Exploring the ambivalent role of social identification as a moderator of intergroup stress in sojourners. International Journal of Intercultural Relations, 60, 1-11. doi:10.1016/j.ijintrel.2017.06.004

Brenner, P. S., \& DeLamater, J. (2016). Measurement directiveness as a cause of response bias: Evidence from two survey experiments. Sociological Methods \& Research, 45(2), 348-371. Retrieved from http://dx.doi.org.proxy1.ncu.edu/10.1177/0049124114558630

Brezis, E. S., \& Hellier, J. (2018). Social mobility at the top and the higher education system. European Journal of Political Economy, 52, 36-54. doi:10.1016/j.ejpoleco.2017.04.005

Brown, L., \& Jones, I. (2013). Encounters with racism and the international student experience. Studies in Higher Education, 38(7), 1004-1019. doi:10.1080/03075079.2011.614940

Butz, N. T., \& Askim-Lovseth, M. K. (2015). Oral communication skills assessment in a synchronous hybrid MBA Programme: Does attending face-to-face matter for US and international students? Assessment \& Evaluation in Higher Education, 40(4), 624-639. doi:10.1080/02602938.2014.940577

Buzzelli, A. (2016). Developing learning outcomes for a collaborative event: Highlighting a recreational soccer tournament designed to connect international and domestic students. Recreational Sports Journal, 40(1), 82-92. doi:10.1123/rsj.2014-0068

Caplan, N. A., \& Stevens, S. G. (2017). "Step out of the cycle": Needs, challenges, and successes of international undergraduates at a U.S. University. English for Specific Purposes, 46, 15-28. doi:10.1016/j.esp.2016.11.003

Chao, R. C., Paiko, L., Zhang, Y. D., \& Zhao, C. (2017). Service-learning: A training method to enhance multicultural competence toward international students. Scholarship of Teaching and Learning in Psychology, 3(1), 28-42. doi:10.1037/st10000078

Charles-Toussaint, G. C., \& Crowson, H. M. (2010). Prejudice against international students: The role of threat perceptions and authoritarian dispositions in U.S. Students. Journal of Psychology, 144(5), 413-428.

Ching, Y., Renes, S. L., McMurrow, S., Simpson, J., \& Strange, A. T. (2017). Challenges facing Chinese international students studying in the United States. Educational Research and Reviews, 12(8), 473-482.

Choudaha, R. (2017). Three waves of international student mobility (1999-2020). Studies in Higher Education, 42(5), 825-832. doi:10.1080/03075079.2017.1293872

Collier, D. A., Rosch, D. M., \& Houston, D. A. (2017). Effects of participation in formal leadership training in international students compared to domestic students: A national study. Journal of Leadership Education, 16(2), 148-165. doi:10.12806/V16/I2/R9 
Creswell, J. W., (2013). Qualitative inquiry and research design: Choosing among five approaches. Thousand Oaks, CA: SAGE.

Doyle, W., \& Zumeta, W. (2014). State-level responses to the access and completion challenge in the new era of austerity. Annals of the American Academy of Political \& Social Science, 655(1), 79-98. doi:10.1177/0002716214534606

Engle, R. L., \& Nash, B. (2016). Foreign travel experience and cultural intelligence: Does country choice matter? Journal of Teaching in International Business, 27(1), 23-40. doi:10.1080/08975930.2016.1173615

Fabricius, A., Mortensen, J., \& Haberland, H. (2017). The lure of internationalization: paradoxical discourses of transnational student mobility, linguistic diversity and cross-cultural exchange. Higher Education, 73(4), 577-595. doi:10.1007/s10734-015-9978-3

Fahad, A. (2015). Sociolinguistic challenges faced by Iraqi graduate students at U.S. universities: A case study for Iraqi graduate students at the University of Cincinnati. Arab World English Journal, 6(1), 366-377.

Foo, C. E., Wells, J. E., \& Walker, N. A. (2015). Do American college and university students endorse the recruitment of international student athletes? Journal of Contemporary Athletics, 9(3), 149-159.

Fuchs, A., Dreher, A., \& Nunnenkamp, P. (2014). Determinants of donor generosity: A survey of the aid budget literature. World Development, 56, 172-199. doi:10.1016/j.worlddev.2013.09.004

Gautam, C., Lowery, C. L., Mays, C., \& Durant, D. (2016). Challenges for global learners: A qualitative study of the concerns and difficulties of international students. Journal of International Students, 6(2), 501-526.

Geary, D. (2016). How do we get people to interact? International students and the American experience. Journal of International Students, 6(2), 527-541.

Harwood, J., Joyce, N., Chen, C., Paolini, S., Xiang, J., \& Rubin, M. (2017). Effects of past and present intergroup communication on perceived fit of an outgroup member and desire for future intergroup contact. Communication Research, 44(4), 530-555. Doi: 10.1177/0093650214565926

Haugen, I., \& Kunst, J. (2017). A two-way process? A qualitative and quantitative investigation of majority members' acculturation. International Journal of Intercultural Relations, 60, 67-82. doi: 10.1016/j.ijintrel.2017.07.004

Healey, N. (2015). Managing international branch campuses: What do we know? Higher Education Quarterly, 69(4), 386-409. https://doi-org.tu.opallibraries.org/10.1111/hequ.12082

Holtbrugge, D., \& Engelhard, F. (2016). Study abroad programs: Individual motivations, cultural intelligence, and the mediating role of cultural boundary spanning. Academy of Management Learning \& Education, 15(3), 435-455. doi:10.5465/amle.2015.0128

Huhn, D., Huber, J., Ippen, F. M., Eckart, W., Junne, F., Zipfel, S., ... Nikendei, C. (2016). International medical students' expectations and worries at the beginning of their medical education: A qualitative focus group study. BMC Medical Education, 16, 33. doi:10.1186/s12909-016-0549-9 
I-Ching, W., Ahn, J. N., Kim, H. J., \& Lin-Siegler, X. (2017). Why do international students avoid communicating with Americans? Journal of International Students, 7(3), 555-580. doi:10.5281/zenodo.570023

Imamura, M., \& Zhang, Y. B. (2014). Functions of the common in-group identity model and acculturation strategies in intercultural communication: American host nationals' communication with Chinese international students. International Journal of Intercultural Relations, 43(Part B), 227-238. doi:10.1016/j.ijintrel.2014.08.018

Institute of International Education. (2018). Top 25 places of origin of International students, 2017-2018. Open Doors Report on international educational exchange. Retrieved from https://www.iie.org/Research-and-Insights/Open-Doors/OpenDoors-2018-Media-Information

Kacowicz, A., \& Mitrain, M. (2016). Why don't we have a coherent theory of international relations about globalization? Global Governance, 22(2), 199-218, doi:10.1163/19425720-02202002

Lee, C., Lee, C., \& Chiou, Y. (2017). Insurance activities, globalization, and economic growth: New methods, new evidence. Journal of International Financial Markets, Institutions \& Money. doi:10.1016/j.intfin.2017.05.006.

Lee, E. J. (2016). International and American students' perceptions of informal English conversations. Journal of International Students, 6(1), 14-34.

Li, Z., Heath, M. A., Jackson, A. P., Allen, G. K., Fischer, L., \& Chan, P. (2017). Acculturation experiences of Chinese international students who attend American universities. Professional Psychology: Research and Practice, 48(1), 11-21. doi:10.1037/pro0000117

Liu, W. (2016). The international mobility of Chinese students: A cultural perspective. Canadian Journal of Higher Education, 46(4), 41-59.

Lombard, C. A. (2014). Coping with anxiety and rebuilding identity: A psychosynthesis approach to culture shock. Counselling Psychology Quarterly, 27(2), 174-199. doi:10.1080/09515070.2013.875887

Macrander, A. (2017). An international solution to a national crisis: Trends in student mobility to the United States post 2008. International Journal of Educational Research, 82, 1-20. doi:10.1016/j.ijer.2016.12.003

McFaul, S. (2016). International students' social network: Network mapping to gage friendship formation and student engagement on campus. Journal of International Students, 6(1), 1-13. Retrieved from http://www.eric.ed.gov/contentdelivery/servlet/ERICServlet

Menashy, F., \& Dryden-Peterson, S. (2015). The Global Partnership for Education's evolving support to fragile and conflict-affected states. International Journal of Educational Development, 44, 82-94. doi:10.1016/j.ijedudev.2015.07.001

Michalec, B., Giordano, C., Dallas, S., \& Arenson, C. (2017). A longitudinal mixedmethods study of IPE students' perceptions of health profession groups: Revisiting the Contact Hypothesis. Journal of Interprofessional Education \& Practice, 6, 71-79. doi:10.1016/j.xjep.2016.12.008

NAFSA (2016). New NAFSA data. International students contribute $\$ 32.8$ billion to the U.S. economy Retrieved from http://www.nafsa.org/About_Us/About_NAFSA/Press/New 
Norman, R. M. G., Windell, D., \& Manchanda, R. (2012). Bogardus Social Distance Scale--Adapted [Database record]. Retrieved from PsycTESTS. Doi: http://dx.doi.org/10.1037/t35129-000

Okeja, U. (2017). Reverse migration, brain drain and global justice. South African Journal of Philosophy, 36(1), 133-143. doi:10.1080/02580136.2016.1275469

Oyserman, D. (2016). What does a priming perspective reveal about culture: cultureas-situated cognition? Current Opinion in Psychology, 12, 94-99. doi:10.1016/j.copsyc.2016.10.002

Pettigrew, T. F., \& Tropp, L. R. (2006). A meta-analytic test of intergroup contact theory. Journal of Personality and Social Psychology, 90(5), 751-783. doi:10.1037/0022-3514.90.5.751

Pfeffer, F. T. (2015). Equality and quality in education. A comparative study of 19 countries. Social Science Research, 51, 350-368. doi:10.1016/j.ssresearch.2014.09.004

Prazeres, L., Findlay, A., McCollum, D., Sander, N., Musil, E., Krisjane, Z., \& Apsite-Berina, E. (2017). Distinctive and comparative places: Alternative narratives of distinction within international student mobility. Geoforum, 80, 114-122. doi:10.1016/j.geoforum.2017.02.003

Presbitero, A. (2017). It's not all about language ability: motivational cultural intelligence matters in call center performance. International Journal of Human Resource Management, 28(11), 1547-1562. doi:10.1080/09585192.2015.1128464

Racicot, B. M., \& Ferry, D. L. (2016). The impact of motivational and metacognitive cultural intelligence on the study abroad experience. Journal of Educational Issues, 2(1), 115-129.

Ramsey, J. R., \& Lorenz, M. P. (2016). Exploring the impact of cross- cultural management education on cultural intelligence, student satisfaction, and commitment. Academy of Management Learning \& Education, 15(1), 79-99. Doi:10.5465/amle.2014.0124

Ramswell, P. (2017). Derision, division-decision: parallels between Brexit and the 2016 US presidential election. European Political Science, 16(2), 2-17. doi:10.1057/s41304-017-0112-0

Rice, K. G., Suh, H., Yang, X., Choe, E., \& Davis, D. E. (2016). The advising alliance for international and domestic graduate students: Measurement invariance and implications for academic stress. Journal of Counseling Psychology, 63(3), 331342. doi:10.1037/cou0000141

Ron, Y., Solomon, J., Halperin, E., \& Saguy, T. (2017). Willingness to engage in intergroup contact: A multilevel approach. Peace and Conflict: Journal of Peace Psychology, 23(3), 210-218. doi:10.1037/pac0000204

Rose-Redwood, C., \& Rose-Redwood, R. (2017). Rethinking the politics of the international student experience in the age of Trump. Journal of International Students, 7(3), I-IX.

Roy, S. K., Balaji, M., Soutar, G., Lassar, W. M., \& Roy, R. (2017). Customer engagement behavior in individualistic and collectivistic markets. Journal of Business Research, doi:10.1016/j.jbusres.2017.06.001. 
Ruble, R. A., \& Zhang, Y. B. (2013). Stereotypes of Chinese international students held by Americans. International Journal of Intercultural Relations, 37, 202211. doi:10.1016/j.ijintrel.2012.12.004

Schumann, S., Klein, O., Douglas, K., \& Hewstone, M. (2017). Full length article: When is computer-mediated intergroup contact most promising? Examining the effect of outgroup members' anonymity on prejudice. Computers in Human Behavior. doi:10.1016/j.chb.2017.08.006

Shammas, D. (2015). We are not all the same: Arab and Muslim students forging their own campus communities in a post-9/11 America. Journal of Muslim Minority Affairs, 35(1), 65-88. doi:10.1080/13602004.2015.1019730

Sheppard, B. E., Elliott, N. C., \& Baese-Berk, M. M. (2017). Comprehensibility and intelligibility of international student speech: Comparing perceptions of university EAP instructors and content faculty. Journal of English for Academic Purposes, 26, 42-51. https://doi-org.tu.opallibraries.org/10.1016/j.jeap.2017.01.006

Shields, R., \& Menashy, F. (2019). The network of bilateral aid to education 20052015. International Journal of Educational Development, 64, 74-80. doi:10.1016/j.ijedudev.2017.07.003

Shu, F., McAbee, S. T., \& Ayman, R. (2017). The HEXACO personality traits, cultural intelligence, and international student adjustment. Personality and Individual Differences, 106, 21-25. doi:10.1016/j.paid.2016.10.024

Stein, S., \& Andreotti, V. (2016). Cash, competition, or charity: international students and the global imaginary. Higher Education, 72(2), 225-239. doi:10.1007/s10734-015-9949-8

Tan, C., \& Chua, C. K. (2015). Education policy borrowing in China: Has the west wind overpowered the east wind? Compare: A Journal of Comparative and International Education, 45(5), 686-704.

Tawagi, A. L., \& Mak, A. S. (2015). Cultural inclusiveness contributing to international students' intercultural attitudes: Mediating role of intergroup contact variables. Journal of Community \& Applied Social Psychology, 25(4), 340-354. doi:10.1002/casp.2218

Van Dyne, L., \& Ang, S. (2008). Handbook of cultural intelligence. Armonk, NY: Routledge.

Van Dyne, L., Ang, S., Ng, K. Y., Rockstuhl, T., Tan, M. L., \& Koh, C. (2012), Subdimensions of the four factor model of cultural intelligence: Expanding the conceptualization and measurement of cultural intelligence. Social and Personality Psychology Compass, 6, 295-313. doi:10.1111/j.1751-9004.2012. 00429.x

Wang, K. T., Heppner, P. P., Wang, L., \& Zhu, F. (2015). Cultural intelligence trajectories in new international students: Implications for the development of cross-cultural competence. International Perspectives in Psychology: Research, Practice, Consultation, 4(1), 51-65. Doi: 10.1037/ipp0000027

White, F. A., Abu-Rayya, H. M., Bliuc, A., \& Faulkner, N. (2015). Emotion expression and intergroup bias reduction between Muslims and Christians: Longterm Internet contact. Computers in Human Behavior, 53, 435-442. doi:10.1016/j.chb.2015.04.074 
World Bank. (2017). World development report. Digital dividends overview. Retrieved from http://documents.worldbank.org/curated/en/961621467994698644/pdf/102724WDR-WDR2016Overview-ENGLISH-WebResBox-394840B-OUO-9.pdf

Wu, T., Perrings, C., Kinzig, A., Collins, J., Minteer, B., \& Daszak, P. (2017). Economic growth, urbanization, globalization, and the risks of emerging infectious diseases in China: A review. AMBIO - A Journal of the Human Environment, 46(1), 18-29. doi:10.1007/s13280-016-0809-2

Yoshii, H., Mandai, N., Saito, H., \& Akazawa, K. (2015). Reliability and validity of the workplace Social Distance Scale. Global Journal of Health Science, 7(3), 4651. Retrieved from http://doi.org/10.5539/gjhs.v7n3p46

Zabo, A., Ward, C., \& Jose, P. E. (2016). Uprooting stress, coping, and anxiety: A longitudinal study of international students. International Journal of Stress Management, 23(2), 190-208. Doi: 10.1037/a0039771

SAMI MEJRI, PhD, is an Assistant Professor of Science and Education in the School of Arts and Sciences at Tiffin University. His major research interests lie in the area of comparative and international education, online learning, virtual learning, and higher education research and multiculturalism. Email: mejris@tiffin.edu 